15 bis 20\% der Menschen werden dagegen offensichtlich von $S$. aureus gemieden.

S.-aureus-Träger haben ein erhöhtes Risiko für staphylogene Hauterkrankungen oder Wundinfektionen. Gefährdet sind vor allem Patienten mit chronischen atopischen Ekzemen der Haut, Patienten mit implantierten Fremdkör- pern, Diabetes mellitus, Granulozytendefekten und Immunglobulin-Mangelsyndrom. Streptokokken der Gruppe A (GAS) und $S$. aureus sind außerdem die häufigsten Erreger von Hautinfektionen nach Reisen - die Risikofaktoren sind hier aber noch nicht identifiziert. Für die Therapie von Staphylokokkeninfektionen der Haut steht jetzt mit Retapamu- lin $\left(\right.$ Altargo $\left.{ }^{\circledR}\right)$ ein neues, sehr gut wirksames Mittel zur Verfügung. Das Topikum ist wirksam gegen Staphylokokken und Streptokokken und erfasst auch Fusidinsäure- und Mupirocin-resistente S.-aureus-Stämme. Die Behandlung dauert fünf Tage.

Plenarvortrag Staphylokokken, 28.7.2010

\section{Morgellons bald auch in Europa?}

Beim Dermatozoenwahn handelt es sich um eine Psychose mit haptischen Halluzinationen. In den USA werden unter den Betroffenen zurzeit sogenannte Morgellons gehandelt. Die erfundenen Tierchen könnten auch bald in deutschen Hautartpraxen zur Sprache kommen.

L ebende Tierchen in der Haut möchte keiner gerne haben. Jedoch lässt sich bei manchen Patienten beim besten Willen nichts finden. Die Diagnose „Dermatozoenwahn“, eine Psychose mit haptischen Halluzinationen, wird von den Patienten nicht akzeptiert, sie gehen zum nächsten Arzt - und publizieren fleißig im Internet. So grassieren in den USA derzeit die Morgellons, eine Variante des Dermatozoenwahns. Auf zahlreichen Homepages kann man sich eingehend über das Leid der Betroffenen informieren. Sicher werden bald auch in Deutschland die ersten Morgellon-Infizierten ihren Hautarzt aufsuchen, prophezeite Prof. Dr. Uwe Gieler, Gießen.

Was tun? Der erste Schritt ist die Differenzialdiagnose „Infektion oder taktile Halluzinose". So wird der Patient mit einer „echten“ Hautinfektion nach einer Erklärung suchen, er ist nicht auf einen Befund fokussiert oder lässt sich zumindest in seinen Annahmen korrigieren, Material wird nicht mitgebracht. Patienten mit taktiler Halluzinose sind dage- gen auf einen Hautbefund fokussiert und darin nicht korrigierbar. Sie bringen $\mathrm{Ma}-$ terial mit und berichten nicht selten von verschiedenen Eigenbehandlungen z. B. mit Anthelminthika. Häufig sind die $\mathrm{Pa}-$ tienten alleinstehend und/oder älter.

Hat sich der Verdacht „taktile Halluzinose/Dermatozoenwahn“ "erhärtet, sind Neuroleptika wie Risperidon oder Olanzapin die Therapeutika der ersten Wahl. Metaanalysen zufolge haben bis zu 75\% der Patienten unter diesen $\mathrm{Me}$ dikamenten eine Vollremission. Eine Psychotherapie bringt dagegen keine Besserung, sagte Gieler. Meist wird der Dermatologe selbst behandeln, sollte sich aber mit einem Psychiater beraten. Die Behandlungsdauer beträgt im Schnitt drei Monate.

Plenarvortrag Unsichtbare Tiere, 28.7.2010

\title{
Borreliose-Impfstoff für Europa lässt 14 weiter auf sich warten
}

Zumindest für Hunde gibt es ihn schon: einen Impfstoff gegen Borreliose. Wie lange wir Menschen noch auf ihn warten müssen, ist noch in der Schwebe.

Z ecken sind Überträger der viralen Frühsommer-Meningoenzephalitis (FSME) und der bakteriellen Borreliose. Gegen die FSME kann seit längerem geimpft werden, die Impfstoffentwicklung für die Borreliose ist dagegen aufgrund der immunologischen Vielgestaltigkeit der Borrelien-Oberflächenstrukturen schwieriger, sagte Prof. Dr. Elisabeth Aberer, Graz. Die derzeit am besten untersuchten Impfstoffe zielen auf Oberflächenproteine (,outer surface proteins", Osps) der verschiedenen Borrelien-Serotypen wie OspA oder OspC.

Ein europäischer Impfstoff gegen Borrelieninfektionen muss eine breite Wirkamkeit besitzen und alle hier vorkommenden Borrelien-Serotypen abdecken. In Nordamerika tritt dagegen nur ein Borrelien-Serotyp auf, gegen den bereits ein Impfstoff entwickelt wurde: LYMErix ${ }^{\circledR}$ ist ein rekombinanter OspA-Impfstoff und in den USA (zunächst einmal) für die Impfung von Hunden zugelassen.
Borrelien-Impfstoffe für den europäischen Raum befinden sich dagegen noch in der klinischen Entwicklung.

bk

Plenarvortrag Zecken und Borrelien, 28.7.2010

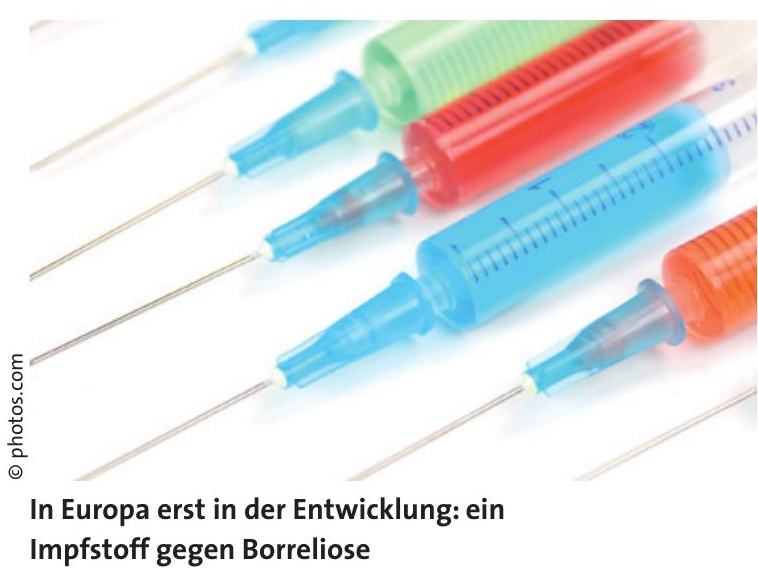

